\title{
Hepcidin Levels and Their Determinants in Different Types of Myelodysplastic Syndromes
}

\author{
Valeria Santini ${ }^{19}$, Domenico Girelli ${ }^{2 * 9}$, Alessandro Sanna ${ }^{1}$, Nicola Martinelli ${ }^{2}$, Lorena Duca ${ }^{3}$, Natascia \\ Campostrini ${ }^{2}$, Agostino Cortelezzi ${ }^{4}$, Michela Corbella ${ }^{2}$, Alberto Bosi ${ }^{1}$, Gianluigi Reda ${ }^{4}$, Oliviero Olivieri ${ }^{2}$, \\ Maria Domenica Cappellini ${ }^{3}$
}

1 Hematology Unit, AOU Careggi, University of Florence, Florence, Italy, 2 Department of Medicine, Section of Internal Medicine, University of Verona, Verona, Italy, 3 Department of Internal Medicine, “Cà Granda" Foundation IRCCS, University of Milan, Milan, Italy, 4 Hematology Unit 1, “Cà Granda" Foundation IRCCS, University of Milan, Milan, Italy

\begin{abstract}
Iron overload may represent an additional clinical problem in patients with Myelodysplastic Syndromes (MDS), with recent data suggesting prognostic implications. Beyond red blood cells transfusions, dysregulation of hepcidin, the key iron hormone, may play a role, but studies until now have been hampered by technical problems. Using a recently validated assay, we measured serum hepcidin in 113 patients with different MDS subtypes. Mean hepcidin levels were consistently heterogeneous across different MDS subtypes, with the lowest levels in refractory anemia with ringed sideroblasts (RARS, $1.43 \mathrm{nM}$ ) and the highest in refractory anemia with excess blasts (RAEB, $11.3 \mathrm{nM}$ ) or in chronic myelomonocytic leukemia (CMML, $10.04 \mathrm{nM})(P=0.003$ by ANOVA). MDS subtypes remained significant predictors of hepcidin in multivariate analyses adjusted for ferritin and transfusion history. Consistently with current knowledge on hepcidin action/regulation, RARS patients had the highest levels of toxic non-transferrin-bound-iron, while RAEB and CMML patients had substantial elevation of C-Reactive Protein as compared to other MDS subtypes, and showed lost of homeostatic regulation by iron. Growth differentiation factor 15 did not appear as a primary hepcidin regulator in this series. If confirmed, these results may help to calibrate future treatments with chelating agents and/or hepcidin modulators in MDS patients.
\end{abstract}

Citation: Santini V, Girelli D, Sanna A, Martinelli N, Duca L, et al. (2011) Hepcidin Levels and Their Determinants in Different Types of Myelodysplastic Syndromes. PLoS ONE 6(8): e23109. doi:10.1371/journal.pone.0023109

Editor: Dan Kaufman, University of Minnesota, United States of America

Received May 18, 2011; Accepted July 6, 2011; Published August 19, 2011

Copyright: (c) 2011 Santini et al. This is an open-access article distributed under the terms of the Creative Commons Attribution License, which permits unrestricted use, distribution, and reproduction in any medium, provided the original author and source are credited.

Funding: This work was supported by Telethon Foundation (Rome, Italy) Grants GGP06213 and the Cariverona Foundation (Verona, Italy) to DG. The funders had no role in study design, data collection and analysis, decision to publish, or preparation of the manuscript.

Competing Interests: The authors have declared that no competing interests exist.

*E-mail: domenico.girelli@univr.it

9 These authors contributed equally to this work.

\section{Introduction}

Myelodysplastic syndromes (MDS) are a heterogeneous group of clonal stem cell disorders characterized by dysplastic and ineffective hematopoiesis, peripheral cytopenias often including severe anemia, and a variable risk of progression to acute myleogenous leukemia (AML) [1].

Iron overload frequently occurs in MDS patients [2], with recent data suggesting an impact on both overall and leukemiafree survival [3]. Though prolonged red blood cells (RBC) transfusion therapy appears the main contributor, many patients appear to develop iron overload at an early stage of the disease, before the onset of transfusions [4]. It has been postulated that an altered production of hepcidin, the recently discovered key hormone regulating iron homeostasis [5], may play a role at this regard [6]. Hepcidin is a small peptide that acts by binding to ferroportin, its receptor highly expressed on the membrane of cells involved in iron handling like iron absorbing duodenal enterocytes and macrophages recycling senescent erythrocytes [7]. Ferroportin, the only known cellular iron exporter in vertebrates, is internalized and degraded after hepcidin binding [8], which results in blocking both dietary iron absorption and the release of iron from macrophages. The regulation of hepcidin is complex and mediated by different stimuli with opposing effects [5,9]. Increased hepatic and plasma iron homeostatically induce hepcidin synthesis, as does inflammation, while erythropoietic activity suppresses the hormone production [9]. The latter is finalized to increase iron supply for erythropoiesis through enhanced iron absorption and release from macrophages. Such effect becomes particularly important in diseases with ineffective erythropoiesis, where erythrocyte precursors massively expand but undergo apoptosis rather than maturing. Growth differentiation factor 15 (GDF-15), a protein produced by erythroid precursors, has been proposed to be a major hepcidin suppressor in $\beta$-thalassemia [10], but data in other conditions with ineffective erythropoiesis are less conclusive [11].

Until recently, clinical studies on hepcidin in humans have been hampered by problems in the development of reliable assays $[12,13]$. Regarding MDS, only scanty and conflicting data based on first generation semi-quantitative measurement of urinary hepcidin have been reported $[14,15]$. We used a recently validated and improved Mass-Spectrometry based method to analyze serum hepcidin levels in MDS patients, also focusing in trying to elucidate its determinants. 


\section{Methods}

\section{Patients}

Patients and controls were enrolled at Internal Medicine and Hematology Units in Verona (Azienda Integrata OspedalieraUniversitaria), Florence (Ospedale Careggi) and Milan (Policlinico), all in Italy. One hundred and thirteen MDS patients (mean age $72.8 \pm 9.2$ years; $68.1 \%$ males) were included. To be enrolled in this study, patients had to be previously untreated or treated only with transfusions. Patients treated at any time with iron chelating agents were excluded. After careful evaluation of transfusion history, patients were defined transfusion-dependent or transfusion-independent according to International Working Group (IWG) criteria [16]. Reliable data in this sense were available for 107/133 patients. MDS subtypes were classified according to World Health Organization (WHO) [17], and stratified for prognosis according to International Prognostic Scoring System (IPSS). To do a comparison with respect to serum hepcidin levels and the hepcidin/ferritin ratio (see below), a group of fifty-four healthy individuals $(61.1 \%$ males $)$ with rigorous definition of normal iron status as previously described in details $[18,19]$, were used as controls. The protocol of this observational study was approved by the Ethical Committee of the Azienda Integrata Ospedaliera Universitaria of Verona, and all subjects gave written informed consent.

\section{Biochemical Assays}

Blood samples were obtained early in the morning after overnight fasting, immediately centrifuged, and serum was stored at $-80^{\circ} \mathrm{C}$ in aliquots to avoid multiple freeze-thaw cycles. Serum iron, transferrin, ferritin, and C-Reactive Protein (CRP) were measured using routine standard laboratory assays.

Serum hepcidin was measured by Surface-Enhanced Laser Desorption/Ionization Time-Of-Flight Mass Spectrometry (SELDITOF MS), using a synthetic hepcidin analogue (Hepdicin-24, Peptides International, Louisville, KY) as an internal standard, as previously described [19], with recent technical advances [20]. The ratio between hepcidin and ferritin, which reflects the homeostatic ability of hepcidin to increase as a response to increased body iron was calculated as previously described [21].

Serum non-transferrin-bound iron (NTBI) was evaluated by chromatographic method as previously described [22]. Briefly, $450 \mu \mathrm{l}$ of serum was added to $50 \mu \mathrm{l}$ of nitrilotriacetic acid $800 \mathrm{mM}$ $(\mathrm{pH} 7.0)$ and allowed to stand for $15 \mathrm{~min}$. The solution was ultrafiltered using an Amicon Centricon 30 microconcentrator and the ultrafiltrate $(20 \mu \mathrm{l})$ was injected directly into the high performance liquid chromatography (HPLC) system with a titanium pump module (Perkin Elmer S200, Boston, MA, USA). The HPLC column used for the determination of NTBI had the following characteristics: Nova-Pak C18, $4 \mu \mathrm{m}, 3.9 \times 150 \mathrm{~mm}$, reversed-phase column produced by Waters (Wexford, Ireland). The chromatographic conditions were the following: Flow rate $1.5 \mathrm{ml} / \mathrm{min}$; mobile phase isocratic containing $20 \%$ acetonitrile and $80 \%$ sodium phosphate buffer, $5 \mathrm{mM}(\mathrm{pH} 7.0)$ containing $3 \mathrm{mM} \mathrm{CP22;} \mathrm{visible} \mathrm{detection,} 450 \mathrm{~nm}$. A standard curve was generated by injecting different concentrations of iron prepared in a 100-fold excess of NTA. The standards were routinely run at 0 to $10 \mathrm{mM}$, although absorbance was linear up to $40 \mathrm{mM}$. Under these conditions, the $0 \mathrm{mM}$ standard corresponds to $80 \mathrm{mM}$ of NTA. The addition of $80 \mathrm{mM}$ of NTA to the serum of normal individuals always results in negative NTBI values. Normal individuals always have negative NTBI values because blank is formed by water and nitrilotriacetic acid; water per se contains small amounts of iron that is not bound by transferrin, whereas in samples, transferrin, which is not completely saturated, captures some iron from the ferritin-nitrilotriacetic acid complex [23].

Serum GDF-15 was determined using a commercially available Duo-Set enzyme-linked immunosorbent assay (ELISA) according to manufacturer's indications (R\&D Systems, Abingdon, Oxfordshire, UK).

Serum erythropoietin (EPO) was determined using a commercially available radioimmunoassay (EPO-Trac ${ }^{125}$ I) kit according to manufacturer's indications (DiaSorin, Stillwater, Minnesota, USA).

\section{Statistical analyses}

All calculations were performed using SPSS 17.0 software (SPSS Inc., Chicago, IL, USA). As many of the continuous variables of interest, including serum hepcidin, ferritin, GDF-15, and EPO, showed a non-Gaussian distribution, their values were logtransformed and expressed as geometric means with 95\% confidence intervals (CIs). Quantitative data were analysed using the Student's t test or by analysis of variance (ANOVA) with polynomial contrast for linear trend, when appropriate. Qualitative data were analyzed with the $\chi^{2}$ test and with $\chi^{2}$ analysis for linear trend, when appropriate. Correlations between quantitative variables were assessed using Pearson's coefficient. Independent determinants of serum hepcidin levels were assessed at first in a linear regression model estimating $\beta$-coefficients including all the variables significantly correlated with hepcidin at univariate analysis (e.g. ferritin, CRP), as well as age, gender, and presence/absence of the diagnosis of MDS. Thereafter, aiming to evaluate the potential heterogeneity in iron/hepcidin homeostasis among the different types of MDS, the latter were codified as dummy variables in linear regression models, adjusted at first for sex, age, history of blood transfusion, and ferritin levels (model 1), then adding CRP levels (model 2). To evaluate the different degree of correlation between hepcidin and ferritin among the different types of MDS, data were analyzed in a general linear model by means of the $\mathrm{F}$ test for slopes. Two-sided $\mathrm{p}$ values $<0.05$ were considered statistically significant.

\section{Results}

\section{MDS patients versus controls}

Table 1 shows the main characteristics and iron biochemical parameters including serum hepcidin of the whole MDS population as compared with the control group. Controls were matched for gender (predominantly males), but were significantly younger than MDS patients. Recent data from our laboratory in a large population study have shown that serum hepcidin levels are consistently stable in males over a wide age range (18-90 years) [24]. Nevertheless, all multivariate analyses on serum hepcidin levels were adjusted for gender. As shown in Table 1, biochemical markers of iron overload (namely serum ferritin and transferrin saturation), as well as CRP levels, were significantly higher in MDS patients as compared to controls. In the whole MDS population serum hepcidin levels were slightly higher than in controls, but this difference did not reach the statistical significance. Nevertheless, the hepcidin/ferritin ratio was significantly lower in the whole MDS population as compared to controls. As regards to serum GDF-15, we could not directly measure this protein in controls, but levels in MDS patients $(4,422 \mathrm{pg} / \mathrm{ml}, 95 \%$ CIs 3,591-5,445) were markedly higher than the manufacturer's reference range $(641 \mathrm{pg} / \mathrm{ml}, 95 \%$ CIs $401-$ 881). The same was true also for serum NTBI and EPO levels (showed in Table S1). 
Table 1. General characteristics of the whole MDS population as compared to a reference group with normal serum iron indices and hepcidin.

\begin{tabular}{|c|c|c|c|}
\hline & Controls $(n=54)$ & MDS $(n=113)$ & $P$ \\
\hline Age (years) & $34.8 \pm 15.8$ & $72.8 \pm 9.2$ & $<0.001$ \\
\hline Male sex (\%) & 61.1 & 68.1 & 0.370 \\
\hline CRP (mg/l) & $1.07(0.93-1.23)$ & $3.81(2.71-5.36)$ & $<0.001$ \\
\hline Ferritin* $(\mu \mathbf{g} / \mathbf{l})$ & 79 (64-97) & $515(407-652)$ & $<0.001$ \\
\hline Hepcidin* (nM/l) & $4.20(3.53-5.00)$ & $5.31(3.98-7.08)$ & 0.288 \\
\hline $\begin{array}{l}\text { Hepcidin/Ferritin } \\
\text { Ratio** }\end{array}$ & $52.94(43.57-64.33)$ & $10.10(7.53-13.53)$ & $<0.001$ \\
\hline s-Iron $(\mu \mathbf{g} / \mathbf{d l})$ & $100 \pm 28$ & $127 \pm 59$ & $<0.001$ \\
\hline s-Transferrin (g/l) & $2.51 \pm 0.37$ & $2.01 \pm 0.40$ & $<0.001$ \\
\hline $\begin{array}{l}\text { Transferrin } \\
\text { Saturation (\%) }\end{array}$ & $28.9 \pm 9.1$ & $49.8 \pm 27.4$ & $<0.001$ \\
\hline
\end{tabular}

*: geometric means with $95 \%$ Confidence Intervals between bracke. doi:10.1371/journal.pone.0023109.t001

\section{Transfusion dependent versus transfusion independent MDS patients}

Biochemical parameters of MDS patients stratified according to the presence or absence of transfusion dependence are shown in Table S1. As expected, transfusion dependent (TD) MDS patients had significantly higher levels of serum ferritin and transferrin saturation as compared to transfusion independent patients. Notably, serum hepcidin levels were significantly higher in TD MDS patients as compared to either controls or non-TD patients, but the hepcidin/ferritin ratio was similar in TD and non-TD MDS patients. TD MDS patients had also significantly higher levels of serum NTBI, GDF-15, and EPO as compared to non-TD patients.

\section{MDS patients stratified according to different WHO subtypes}

Table 2 shows the clinical and biochemical characteristics of the MDS patients stratified according to the WHO classification. Serum hepcidin levels showed a significant variability across the different MDS subtypes ( $\mathrm{P}=0.003$ by ANOVA), with the lowest values in patients with refractory anemia with ringed sideroblasts (RARS) and the highest values in subjects with refractory anemia with excess blasts (RAEB) and in patients with chronic myelomonocytic leukemia (CMML). The hepcidin/ferritin ratio (also showed in Figure $\mathrm{S} 1$ ) was also markedly heterogeneous across the different MDS subtypes. It was remarkably lower not only in RARS but also in patients with the $5 \mathrm{q}$ - syndrome, while CMML patients showed the highest values ( $\mathrm{P}=0.003$ by ANOVA). Of note, patients with RARS and with the 5q- syndrome also appeared as the most iron overloaded, as suggested by the trend toward higher levels not only of serum ferritin, but also of serum transferrin saturation $(\mathrm{P}=0.048$ by ANOVA) and serum NTBI. As regards to serum GDF-15 levels, they were consistently homogeneous across the different MDS subtypes $(\mathrm{P}=0.976$ by ANOVA). GDF-15 did not correlate at all with hepcidin levels $(\mathrm{r}=-0.07 ; \mathrm{P}=0.48)$. On the contrary, CRP levels were significantly heterogeneous in different MDS subtypes $(\mathrm{P}=0.008$ by ANOVA), with the highest values in patients with RAEB, CMML and in those unclassified. Table $\mathrm{S} 2$ shows the biochemical parameters in MDS patients stratified according to the IPSS.

\section{Homeostatic control of hepcidin by iron}

To explore the degree of preservation of the homeostatic control of hepcidin by iron, we performed a set of general linear models. As shown in Figure 1A, when considering the MDS population as a whole, the positive correlation between hepcidin and ferritin was relatively conserved, though the hepcidin/ferritin ratio was lower than in controls suggesting a relatively blunted response. However, when MDS patients were stratified according to the different WHO subtypes a marked heterogeneity of slopes was evident (Figure 1B). This suggested the relative preservation of the homeostatic control by iron in certain MDS subtypes like RA (Figure 2A), RARS and the 5q- syndrome (Figure 2B), as well as the near complete loss of this mechanism in other MDS subtypes like RAEB and CMML (Figure 2C). Noteworthy, comparing the extremes of such models, i.e. RAEB and CMML versus RARS and 5q-, a significant difference in hepcidin/ferritin slopes was found $(\mathrm{F}=8.684 ; \mathrm{P}=0.005)$.

\section{Hepcidin determinants in MDS patients}

To evaluate the independent determinants of serum hepcidin levels in MDS patients we performed multivariate linear regression models including possible confounders like age, gender, and transfusion history (Table 3). Of note, serum ferritin levels remained as significant predictors of serum hepcidin levels, as did MDS subtypes. More precisely, when compared with RA (considered as reference subtype), RARS (with a negative $\beta$ coefficient), RAEB, and CMML (with a positive $\beta$-coefficient) were independent predictors of serum hepcidin levels (Table 3, model 1). When CRP levels were added to the model, they also were significant independent predictors of hepcidin levels along with ferritin, while the MDS subtypes with high CRP levels (RAEB and CMML) were no longer significant predictors, and the RARS subtype remained significantly associated with hepcidin (Table 3, model 2).

\section{Discussion}

Although percentage of marrow blasts, cytogenetic abnormalities, and cytopenias remain the prognostic cornerstones in MDS, recent data point to iron overload as an important contributing factor. Transfusion dependency have been introduced in the WHO based prognostic score [3], and serum ferritin levels have been associated to either overall or leukemia-free survival [25]. Beyond the classic detrimental effect of cardiac siderosis [26], other iron overload-related mechanisms have been proposed, including an increased risk of infections, adverse effects on hematopoietic stem cell transplantation, and a pro-oxidative state promoting genomic instability and leukemic transformation [6]. Thus, elucidating the pathophysiology of iron overload beyond the obvious role of RBC transfusions represents a relevant issue in MDS patients, with possible therapeutic implications in selecting those patients that may benefit at most from iron chelation therapy [27-29]. As a general rule, an important factor in determining iron toxicity is represented by the route by which the element enter the body, which in turn is unable to excrete excess iron. The parenteral route, i.e. through RBC transfusions, leads to prominent macrophage iron overload that tends to be better tolerated than the intestinal route, leading to prominent overload in periportal hepatocytes and thereafter in other parenchymal cells [30]. Given its pivotal role in orchestrating both iron absorption and recycling from macrophages, hepcidin has been an attractive candidate for studying perturbed iron homeostasis in MDS, but few and contradictory data have been available until now. Winder and colleagues [14] studied 16 MDS patients (4 RA, 3 RARS, 3 
Table 2. Clinical and biochemical characteristics of MDS patients stratified according to WHO classification system.

\begin{tabular}{|c|c|c|c|c|c|c|c|c|}
\hline & $\begin{array}{l}R A \\
(n=31)\end{array}$ & $\begin{array}{l}\text { RARS } \\
(n=9)\end{array}$ & $\begin{array}{l}\text { RCMD } \\
(n=19)\end{array}$ & $\begin{array}{l}\text { RAEB } \\
(n=32)\end{array}$ & $\begin{array}{l}\text { 5q- syndrome } \\
(\mathrm{n}=7)\end{array}$ & $\begin{array}{l}\text { CMML } \\
(n=7)\end{array}$ & $\begin{array}{l}\text { Unclass } \\
(n=8)\end{array}$ & $P$ \\
\hline Age (years) & $75.8 \pm 10.3$ & $73.4 \pm 7.7$ & $73.7 \pm 7.1$ & $70.2 \pm 7.6$ & $71.4 \pm 12.0$ & $73.0 \pm 8.2$ & $67.1 \pm 13.0$ & 0.163 \\
\hline Male sex (\%) & 61.3 & 44.4 & 73.7 & 78.1 & 57.1 & 85.7 & 62.5 & 0.397 \\
\hline CRP* (mg/l) & $\begin{array}{l}2.09 \\
(1.07-4.10)\end{array}$ & $\begin{array}{l}1.46 \\
(0.36-5.56)\end{array}$ & $\begin{array}{l}3.30 \\
(1.37-7.97)\end{array}$ & $\begin{array}{l}9.13 \\
(5.41-15.39)\end{array}$ & $\begin{array}{l}2.21 \\
(0.53-9.13)\end{array}$ & $\begin{array}{l}5.03 \\
(0.19-129.90)\end{array}$ & $\begin{array}{l}10.77 \\
(5.16-22.48)\end{array}$ & 0.008 \\
\hline Ferritin* $(\mu \mathrm{g} / \mathrm{l})$ & $\begin{array}{l}368 \\
(231-586)\end{array}$ & $\begin{array}{l}725 \\
(403-1305)\end{array}$ & $\begin{array}{l}420 \\
(230-768)\end{array}$ & $\begin{array}{l}661 \\
(461-947)\end{array}$ & $\begin{array}{l}1364 \\
(233-8001)\end{array}$ & $\begin{array}{l}289 \\
(130-646)\end{array}$ & $\begin{array}{l}580 \\
(135-2493)\end{array}$ & 0.104 \\
\hline Hepcidin* (nmol/I) & $\begin{array}{l}3.46 \\
(2.06-5.81)\end{array}$ & $\begin{array}{l}1.43 \\
(0.51-4.03)\end{array}$ & $\begin{array}{l}3.83 \\
(1.85-7.96)\end{array}$ & $\begin{array}{l}11.31 \\
(7.38-17.32)\end{array}$ & $\begin{array}{l}6.62 \\
(1.26-34.84)\end{array}$ & $\begin{array}{l}10.04 \\
(2.10-48.00)\end{array}$ & $\begin{array}{l}6.06 \\
(1.18-31.27)\end{array}$ & 0.003 \\
\hline $\begin{array}{l}\text { Hepcidin/Ferritin* } \\
\text { Ratio }(\mathrm{nmol} / \mu \mathrm{g} \times 1000)\end{array}$ & $\begin{array}{l}9.39 \\
(5.72-15.41)\end{array}$ & $\begin{array}{l}1.97 \\
(0.86-4.52)\end{array}$ & $\begin{array}{l}9.13 \\
(3.97-20.95)\end{array}$ & $\begin{array}{l}16.69 \\
(9.73-28.63)\end{array}$ & $\begin{array}{l}4.85 \\
(2.63-8.96)\end{array}$ & $\begin{array}{l}34.68 \\
(6.10-197.22)\end{array}$ & $\begin{array}{l}10.45(2.63- \\
41.45)\end{array}$ & 0.003 \\
\hline $\mathrm{Hb}(\mathrm{g} / \mathrm{dl})$ & $10.62 \pm 2.08$ & $10.18 \pm 1.00$ & $10.31 \pm 1.40$ & $9.07 \pm 1.24$ & $10.90 \pm 2.30$ & $9.44 \pm 1.39$ & $10.39 \pm 1.87$ & 0.008 \\
\hline $\begin{array}{l}\text { Platelet count } \\
\text { (n. cell } \times 10^{9} / \text { ) }\end{array}$ & $165.35 \pm 99.01$ & $411.78 \pm 283.70$ & $270.84 \pm 641.14$ & $91.53 \pm 66.38$ & $122.57 \pm 71.82$ & $82.57 \pm 63.47$ & $35.86 \pm 32.58$ & 0.051 \\
\hline LDH* $^{*}(\mathrm{U} / \mathrm{I})$ & $\begin{array}{l}321 \\
(258-399)\end{array}$ & $\begin{array}{l}304 \\
(255-362)\end{array}$ & $\begin{array}{l}371.85 \\
(284-488)\end{array}$ & $\begin{array}{l}280 \\
(227-346)\end{array}$ & $\begin{array}{l}283 \\
(243-329)\end{array}$ & $\begin{array}{l}403 \\
(156-1042)\end{array}$ & $\begin{array}{l}430 \\
(128-1441)\end{array}$ & 0.393 \\
\hline NTBI $(\mu \mathbf{M})$ & $0.01 \pm 1.15$ & $1.59 \pm 1.96$ & $-0.32 \pm 1.25$ & $0.03 \pm 1.55$ & $0.65 \pm 1.82$ & $0.19 \pm 1.24$ & $0.60 \pm 1.92$ & 0.058 \\
\hline s-Iron $(\mu \mathbf{g} / \mathbf{d l})$ & $117 \pm 53$ & $153 \pm 69$ & $117 \pm 55$ & $131 \pm 64$ & $159 \pm 67$ & $126 \pm 55$ & $114 \pm 43$ & 0.441 \\
\hline s-Transferrin (g/l) & $212 \pm 38$ & $180 \pm 29$ & $209 \pm 46$ & $191 \pm 38$ & $191 \pm 41$ & $209 \pm 28$ & $203 \pm 50$ & 0.219 \\
\hline $\begin{array}{l}\text { Transferrin } \\
\text { saturation (\%) }\end{array}$ & $41.7 \pm 23.4$ & $68.4 \pm 28.6$ & $44.4 \pm 23.9$ & $51.9 \pm 28.2$ & $71.7 \pm 35.2$ & $48.9 \pm 26.9$ & $45.7 \pm 26.1$ & 0.048 \\
\hline GDF-15* (pg/ml) & $\begin{array}{l}3852 \\
(2608-5687)\end{array}$ & $\begin{array}{l}4793 \\
(2144-10714)\end{array}$ & $\begin{array}{l}4630 \\
(2408-8904)\end{array}$ & $\begin{array}{l}4846 \\
(3284-7151)\end{array}$ & $\begin{array}{l}5636 \\
(1905-16677)\end{array}$ & $\begin{array}{l}3938 \\
(2225-6972)\end{array}$ & $\begin{array}{l}3971 \\
(1161-13585)\end{array}$ & 0.976 \\
\hline EPO* (U/I) & $\begin{array}{l}37.50 \\
(14.56-96.54)\end{array}$ & $\begin{array}{l}134.24 \\
(51.61-349.15)\end{array}$ & $\begin{array}{l}82.62 \\
(35.96-189.62)\end{array}$ & $\begin{array}{l}232.87 \\
(149.55-362.64)\end{array}$ & $\begin{array}{l}187.82 \\
(46.04-766.24)\end{array}$ & $\begin{array}{l}88.46 \\
(17.75-440.76)\end{array}$ & $\begin{array}{l}83.89 \\
(11.29-623.34)\end{array}$ & 0.011 \\
\hline \multicolumn{9}{|l|}{ IPSS (\%) } \\
\hline low & 63.0 & 100.0 & 61.1 & 0.0 & 85.7 & 50.0 & 33.3 & \\
\hline int-1 & 33.3 & 0.0 & 38.9 & 34.5 & 14.3 & 33.3 & 33.3 & \\
\hline int-2 & 3.7 & 0.0 & 0.0 & 51.7 & 0.0 & 16.7 & 33.3 & $<0.001$ \\
\hline high & 0.0 & 0.0 & 0.0 & 13.8 & 0.0 & 0.0 & 0.0 & \\
\hline $\begin{array}{l}\text { Transfused } \\
\text { patients (\%) }\end{array}$ & 29.6 & 33.3 & 27.8 & 56.3 & 33.3 & 57.1 & 50.0 & 0.303 \\
\hline
\end{tabular}

: by Analysis of Variance (ANOVA) or by $\chi 2$-analysis, when indicated.

*: variables not normally distributed are expressed as geometric means with $95 \% \mathrm{Cls}$.

doi:10.1371/journal.pone.0023109.t002

RCMD, and 6 RAEB) 13 of them chronically transfused and found undetectable or inappropriately low urinary hepcidin in most of them. These Authors suggested that hepcidin suppression through increased erythropoietic drive, and the ensuing increased iron absorption may be generalized phenomena in MDS. Murphy and colleagues [15] were unable to confirm these data in 17 low grade MDS patients (8 transfusion dependent and 7 treated with EPO), most of them showing normal, if not increased, urinary hepcidin levels. Besides the very limited patients series, both these studies suffered from methodological drawbacks, since they employed first generation semi-quantitative assays of urinary hepcidin that have been abandoned because of insufficient precision [13]. To the best of our knowledge this is the largest study on hepcidin levels in MDS conducted so far. Moreover, it takes advantage from the use of a validated quantitative MS-based assay [19], recently further improved [20]. Contrary to the prior hypothesis of a generalized hepcidin suppression, the main message from our data is that hepcidin production in MDS is consistently heterogeneous, a condition that appears to parallel the clinical and pathological heterogeneity of MDS by themselves. This is also in agreement with in vitro experiments showing a marked variability of sera from MDS patients in their ability to suppress hepcidin in a hepatocyte cell line [31]. The spectrum of hepcidin levels varied broadly from conditions with mean levels less than a half of those in controls, like RARS, to other ones with mean levels more than twice of controls, like RAEB and CMML (Table 2). As regards to the homeostatic control of hepcidin by iron, a similar heterogeneity was evident. Although the hepcidin/ ferritin ratio showed a generalized trend toward a relatively inappropriate response, the homeostatic control by iron appeared relatively conserved in MDS subtypes generally considered at low risk (like RA, RARS and the 5q- syndrome), while it appeared almost completely lost in conditions prominent dysmyelopoiesis like RAEB and CMML. Since multivariate analyses showed that CRP was also an independent determinant of hepcidin levels in MDS along with ferritin and MDS subtypes, we could hypothesize the observed hepcidin heterogeneity as the result of the relative strength of opposing stimuli in different clinical and pathological conditions (Figure 3). The main actors in this sense may be represented by the suppressing effect from ineffective erythropoiesis, variably counterbalanced by the stimulating effects from either increased iron stores or cytokines, of whom CRP is a 


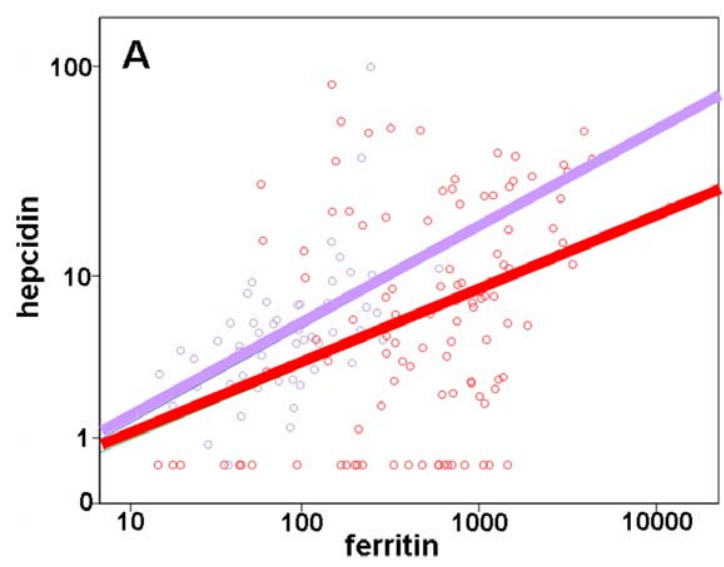

Controls: beta-coefficient $=0.529$; $\mathrm{P}<0.001$

Cases: beta-coefficient 0.391 ; $\mathrm{P}<0.001$

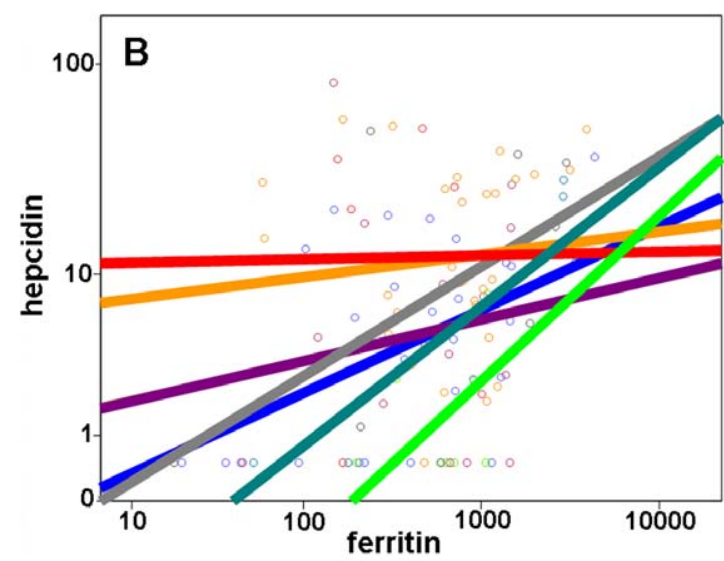

CMML: beta-coefficient $=0.055$; $\mathrm{P}=0.952$

RAEB: beta-coefficient $=0.104$; $\mathrm{P}=0.649$

RCMD: beta-coefficient $=0.285$ $\mathrm{P}=0.333$

RA: beta-coefficient $=0.558$; $\mathrm{P}=0.004$

Unclass.: beta-coefficient $=0.686$; $\mathrm{P}=0.108$

5q- syndrome: beta-coefficient $=0.880$; $\mathrm{P}=0.002$

RARS: beta-coefficient $=1.059$; $\mathrm{P}=0.088$

Figure 1. Correlation plot between hepcidin and serum ferritin levels (logarithmic scale). (A) Controls versus all MDS patients. (B) MDS patients stratified according to WHO classification. doi:10.1371/journal.pone.0023109.g001

surrogate measure. RARS may represent the prototype of MDS where the inhibition from the erythropoietic drive tends to prevail, only partially balanced by the RBC transfusions, either directly or indirectly through increased iron stores. This condition, characterized by the lowest hepcidin/ferritin ratio, indeed showed also the highest values of biochemical iron parameters indicating both an expansion of the plasma iron pool through increased absorption/recycling and parenchymal iron toxicity, like transferrin saturation [32,33] and NTBI. Of note, studies from Mariani and colleagues on hepatic hepcidin mRNA in two RARS patients showed low levels consistent with this view [34]. At the other end of the spectrum lies RAEB and CMML, where the highest levels of both hepcidin/ferritin ratio and CRP may mirror hepcidin stimulation through blast-derived cytokines that overcomes controls by iron. Consistently with this hypothesis, both RAEB and CMML lost their significant predictivity on hepcidin level in a multivariate model adjusted with CRP levels. In this condition, the relative excess of hepcidin could favour iron entrapment within macrophages, limiting toxicity due to uncontrolled release of the element into the plasma and redirection to parenchymal cells.

As regards to the hepcidin suppression from the erythropietic drive, our results argue against a role of GDF-15 as the putative mediator of this biological effect in MDS, at variance with what observed in thalassemic syndromes [10]. GDF-15, also known as bone morphogenetic protein (BMP) 14, is a secreted morphogen of the transforming growth factor-beta super-family, conferring signaling by activation of Smad $1 / 5 / 8$ or mitogen-activated protein kinase (p38-MAPK) [35]. It is highly expressed by erythroid precursors in conditions of ineffective erythropoiesis, but barely detectable in normal bone marrow [11]. In our series, which again is the largest so far evaluating GDF-15 in MDS, mean serum levels of this protein were near six to ten-fold higher than reference values, with a relative homogeneity across different MDS subtypes. Ramirez et al. [36] measured serum GDF-15 in a specific study limited to twenty RARS patients, finding similar levels $(3254 \pm 1400 \mathrm{ng} / \mathrm{ml})$ to our RARS series. Of note, this fascinating and pleiotropic biomarker has been consistently associated also to cardiovascular diseases in recent studies $[37,38]$, an issue that might merit further consideration in the future within the specific context of MDS. Nevertheless, GDF-15 was not correlated at all with hepcidin levels in our series. The apparent discrepancy of our results with those of Tanno and coworkers in thalassemia [10] may be explained in terms of absolute levels. Indeed, the GDF-15 levels reported in thalassemic patients are consistently higher (up to more than $100,000 \mathrm{pg} / \mathrm{ml}$ ) than those found in our MDS series (mean levels near 4,500 pg/ml), and in vitro studies have shown that significant hepcidin suppression requires very high levels, i.e. no less than 5,000 pg/ $\mathrm{ml}$, being still incomplete at the highest dose of $100,000 \mathrm{pg} / \mathrm{ml}$ [10]. Recent expression studies in erythroblasts [39] have shown that erythroid regulation of hepcidin may be an heterogeneous phenomenon mediated by other molecules, i.e. TWSG1 (Twisted Gastrulation) for which serum assay is not yet available. Further studies are needed to clarify which mediators may play a role in hepcidin suppression at least in certain MDS subtypes, particularly in RARS [34]. The observation that iron biochemical parameters 

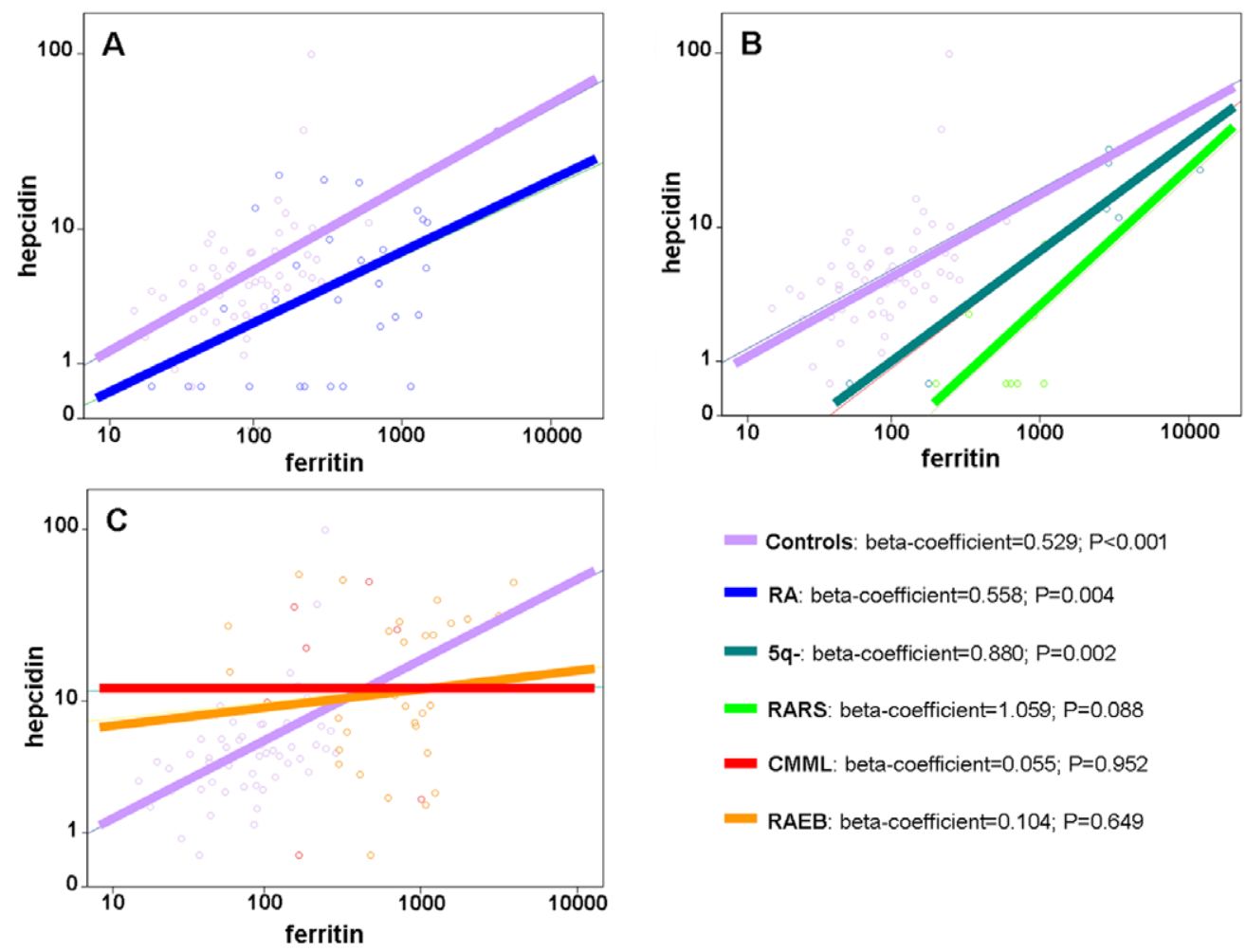

Figure 2. Correlation plot between serum hepcidin and serum ferritin levels in different MDS subtypes as compared to controls (logarithmic scale). (A) Controls versus RA. (B) Controls versus 5q- syndrome and RARS. (C) Controls versus CMML and RAEB. doi:10.1371/journal.pone.0023109.g002

are significantly higher than in controls also in our subset of non transfused patients (Table S1), also reported by others [27] is a further argument in favour of a certain degree of iron hyperabsorption in MDS.

Our study suffers of several limitations that need to be acknowledged. First, our considerations on hepcidin regulation by iron rely on ferritin levels, which are known to be an imperfect marker of iron stores [40]. Other measures of body iron stores such as liver iron content (LIC) through Magnetic Resonance (MR) $[41,42]$ may be more accurate, considering that the "gold standard" represented by liver biopsy is clearly unfeasible in thrombocytopenic and generally elderly patients with several

Table 3. Predictors of hepcidin levels in different linear regression models in MDS patients.

\begin{tabular}{|c|c|c|c|c|}
\hline & \multicolumn{2}{|l|}{ Model $1 \S$} & \multicolumn{2}{|l|}{ Model $2 \wedge$} \\
\hline & $\beta$-coefficient & $P$ & $\beta$-coefficient & $P$ \\
\hline Female sex & 0.474 & 0.129 & 0.408 & 0.227 \\
\hline Age (years) & 0.023 & 0.135 & 0.019 & 0.226 \\
\hline Ferritin $(\mu \mathrm{g} / \mathrm{l})$ & 0.450 & $<0.001$ & 0.451 & 0.002 \\
\hline \multicolumn{5}{|c|}{ Myelodysplastic syndrome subtype * } \\
\hline RARS & -1.245 & 0.019 & -1.181 & 0.024 \\
\hline RCMD & 0.165 & 0.684 & -0.152 & 0.718 \\
\hline RAEB & 1.015 & 0.008 & 0.711 & 0.087 \\
\hline 5q- syndrome & 0.321 & 0.616 & 0.205 & 0.746 \\
\hline CMML & 1.282 & 0.028 & 0.784 & 0.235 \\
\hline Unclass. & 0.502 & 0.367 & 0.270 & 0.648 \\
\hline Blood transfusion & -0.181 & 0.538 & 0.066 & 0.830 \\
\hline CRP (mg/l) & & & 0.210 & 0.020 \\
\hline
\end{tabular}

*: considering RA as the reference group.

§: linear regression model adjusted for sex, age, ferritin levels, MDS type and history of blood transfusion (model 1).

$:$ linear regression model adjusted for the above mentioned factors and CRP levels (model 2 ).

doi:10.1371/journal.pone.0023109.t003 


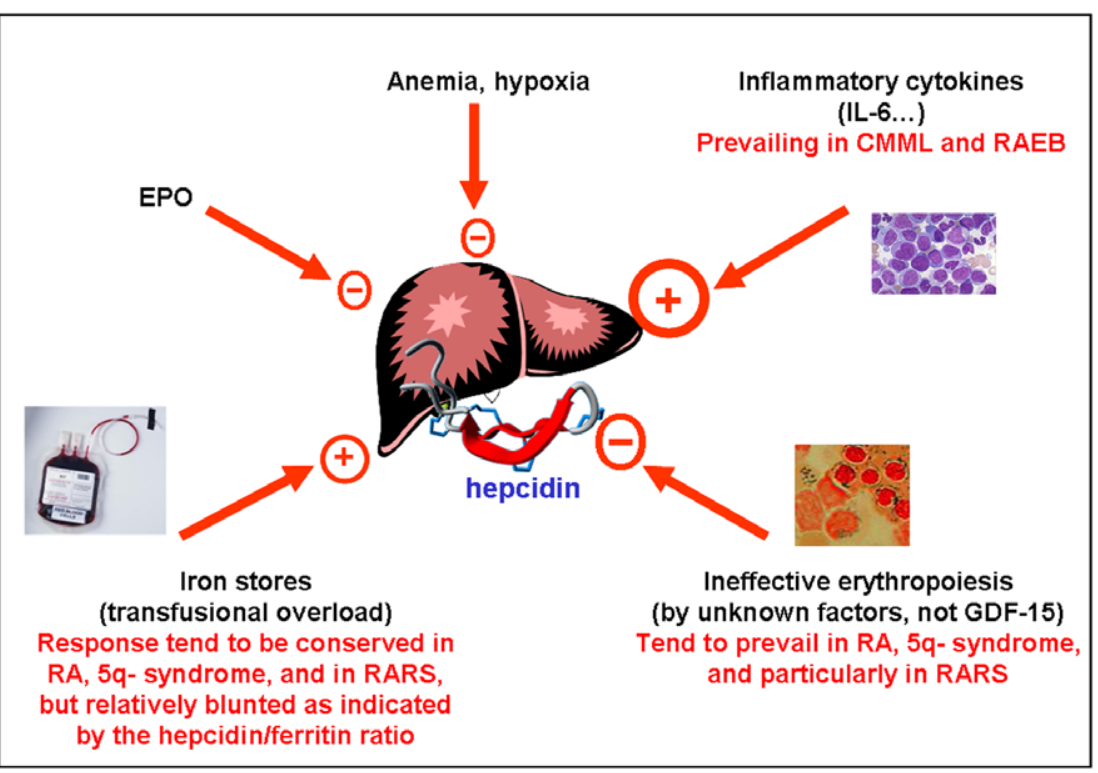

Figure 3. Proposed mechanisms controlling hepcidin production in different MDS subtypes. doi:10.1371/journal.pone.0023109.g003

comorbidities like those with MDS. Nevertheless, recent data by Armand and colleagues [43] indicate that serum ferritin is still an acceptable marker of iron stores in MDS, since it showed a strong and significant correlation $(\mathrm{r}=0.75, \mathrm{P}<0.001)$ with estimated LIC by MR. Similarly, although our hepcidin assay is specific for the 25-mer bioactive isoform and has been clinically validated in other settings $[19,20,44,45]$, we have to recognize that we still lack a gold standard for measuring this hormone in biological fluids [12]. Finally, the effect of inflammatory cytokines [46,47], which may play a prominent role in certain MDS subtypes with excess myeloblast activation, could be studied only indirectly, through a surrogate like CRP.

Notwithstanding these limitations our results, if confirmed, may be relevant for a better understanding of iron pathophysiology in MDS. They point toward an heterogeneity that, like in any one physiological situation, is determined by the relative strengths of competing stimuli in different MDS subtypes (Figure 3), with possible implications also at the individual level. This may help to calibrate possible future therapeutic approaches in MDS patients with either iron chelators $[6,29]$ or hepcidin modulators $[48,49]$.

\section{References}

1. Tefferi A, Vardiman JV (2009) Myelodysplastic syndromes. N Engl J Med 361: 1872-1885.

2. Fenaux P, Rose C (2009) Impact of iron overload in myelodysplastic syndromes. Blood Rev 23 Suppl 1: S15-19.

3. Malcovati L, Porta MG, Pascutto C, Invernizzi R, Boni M, et al. (2005) Prognostic factors and life expectancy in myelodysplastic syndromes classified according to WHO criteria: a basis for clinical decision making. J Clin Oncol 23: 7594-7603.

4. Cortelezzi A, Cattaneo C, Cristiani S, Duca L, Sarina B, et al. (2000) Nontransferrin-bound iron in myelodysplastic syndromes: a marker of ineffective erythropoiesis? Hematol J 1: 153-158.

5. Ganz T, Nemeth E (2011) Hepcidin and disorders of iron metabolism. Annu Rev Med 62: 347-360.

6. Pullarkat V (2009) Objectives of iron chelation therapy in myelodysplastic syndromes: more than meets the eye? Blood 114: 5251-5255.

7. Donovan A, Lima CA, Pinkus JL, Pinkus GS, Zon LI, et al. (2005) The iron exporter ferroportin/Slc40al is essential for iron homeostasis. Cell Metab 1: $191-200$.

\section{Supporting Information}

Figure S1 Mean levels of serum hepcidin, serum ferritin, and hepcidin/ferritin ratio across different MDS subtypes. * : for hepcidin/ferritin ratio, $\mathrm{P}<0.001$ by ANOVA with polynomial contrasts for linear trend.

(TIF)

Table S1 Biochemical parameters of the MDS patients (either as whole population or stratified into transfused or non-transfused groups) as compared to sex-matched healthy controls.

(DOC)

Table S2 Glinical and biochemical characteristics of MDS patients stratified according to the IPSS.

(DOC)

\section{Author Contributions}

Conceived and designed the experiments: VS DG MDC. Performed the experiments: NC MC. Analyzed the data: AS LD AC AB GR NM NC MC. Contributed reagents/materials/analysis tools: VS DG MDC OO AS LD AC AB GR NM. Wrote the paper: VS DG MDC. Contributed to data interpretation and critically revised the manuscript: OO.

8. Nemeth E, Tuttle MS, Powelson J, Vaughn MB, Donovan A, et al. (2004) Hepcidin regulates cellular iron efflux by binding to ferroportin and inducing its internalization. Science 306: 2090-2093.

9. Hentze MW, Muckenthaler MU, Galy B, Camaschella C (2010) Two to tango: regulation of Mammalian iron metabolism. Cell 142: 24-38.

10. Tanno T, Bhanu NV, Oneal PA, Goh SH, Staker P, et al. (2007) High levels of GDF15 in thalassemia suppress expression of the iron regulatory protein hepcidin. Nat Med 13: 1096-1101.

11. Tanno T, Noel P, Miller JL (2010) Growth differentiation factor 15 in erythroid health and disease. Curr Opin Hematol 17: 184-190.

12. Kroot JJ, Kemna EH, Bansal SS, Busbridge M, Campostrini N, et al. (2009) Results of the first international round robin for the quantification of urinary and plasma hepcidin assays: need for standardization. Haematologica 94: 1748-1752.

13. Castagna A, Campostrini N, Zaninotto F, Girelli D (2010) Hepcidin assay in serum by SELDI-TOF-MS and other approaches. J Proteomics 73: 527-536.

14. Winder A, Lefkowitz R, Ghoti H, Leiba M, Ganz T, et al. (2008) Urinary hepcidin excretion in patients with myelodysplastic syndrome and myelofibrosis. Br J Haematol 142: 669-671. 
15. Murphy PT, Mitra S, Gleeson M, Desmond R, Swinkels DW (2009) Urinary hepcidin excretion in patients with low grade myelodysplastic syndrome. Br J Haematol 144: 451-452.

16. Cheson BD, Greenberg PL, Bennett JM, Lowenberg B, Wijermans PW, et al. (2006) Clinical application and proposal for modification of the International Working Group (IWG) response criteria in myelodysplasia. Blood 108: 419-425.

17. Vardiman JW, Harris NL, Brunning RD (2002) The World Health Organization (WHO) classification of the myeloid neoplasms. Blood 100: 2292-2302.

18. Bozzini C, Campostrini N, Trombini P, Nemeth E, Castagna A, et al. (2008) Measurement of urinary hepcidin levels by SELDI-TOF-MS in HFEhemochromatosis. Blood Cells Mol Dis 40: 347-352.

19. Swinkels DW, Girelli D, Laarakkers C, Kroot J, Campostrini N, et al. (2008) Advances in quantitative hepcidin measurements by time-of-flight mass spectrometry. PLoS One 3: e2706.

20. Campostrini N, Castagna A, Zaninotto F, Bedogna V, Tessitore N, et al. (2010) Evaluation of hepcidin isoforms in hemodialysis patients by a proteomic approach based on SELDI-TOF-MS. J Biomed Biotechnol 2010: 329646.

21. Nemeth E, Ganz T (2006) Hepcidin and iron-loading anemias. Haematologica 91: $727-732$.

22. Porter JB, Rafique R, Srichairatanakool S, Davis BA, Shah FT, et al. (2005) Recent insights into interactions of deferoxamine with cellular and plasma iron pools: Implications for clinical use. Ann N Y Acad Sci 1054: 155-168.

23. Gosriwatana I, Loreal O, Lu S, Brissot P, Porter J, et al. (1999) Quantification of non-transferrin-bound iron in the presence of unsaturated transferrin. Anal Biochem 273: 212-220.

24. Traglia M, Girelli D, Biino G, Campostrini N, Corbella M, et al. (2011) The association of HFE and TMPRSS6 genetic variants to iron and erythrocyte parameters is only in part dependent from serum hepcidin levels. J Med Genet, In press.

25. Malcovati L, Della Porta MG, Cazzola M (2006) Predicting survival and leukemic evolution in patients with myelodysplastic syndrome. Haematologica 91: $1588-1590$.

26. Buja LM, Roberts WC (1971) Iron in the heart: etiology and clinical significance. Am J Med 51: 209-221.

27. Gattermann N (2007) Guidelines on iron chelation therapy in patients with myelodysplastic syndromes and transfusional iron overload. Leuk Res 31: S10-15.

28. Bennett JM (2008) Consensus statement on iron overload in myelodysplastic syndromes. Am J Hematol 83: 858-861.

29. Rose C, Brechignac S, Vassilief D, Pascal L, Stamatoullas A, et al. (2010) Does iron chelation therapy improve survival in regularly transfused lower risk MDS patients? A multicenter study by the GFM (Groupe Francophone des Myélodysplasies). Leuk Res 34: 864-870.

30. Piperno A (1998) Classification and diagnosis of iron overload. Haematologica 83: 447-455.

31. Breda L, Ghoti H, Rivella S, Rechavi G, Cabantchik I, et al. (2007) Expression of genes regulating iron metabolism in hepatocyte cell-line HepG2 induced by sera from MDS patients. Blood 110: 4612a.

32. Finch CA, Huebers H (1982) Perspectives in iron metabolism. N Engl J Med 306: 1520-1528.
33. Cazzola M, Della Porta MG, Malcovati L (2008) Clinical relevance of anemia and transfusion iron overload in myelodysplastic syndromes. Hematology Am Soc Hematol Educ Program. pp 166-175.

34. Mariani R, Pelucchi S, Pozzi M, Paolini V, Piperno A (2008) Reduced expression of hepcidin in patients with myelodysplastic syndrome and myelofibrosis: the causes might be more heterogeneous than in thalassaemia. Br J Haematol 143: 746-747.

35. Bootcov MR, Bauskin AR, Valenzuela SM, Moore AG, Bansal M, et al. (1997) MIC-1, a novel macrophage inhibitory cytokine, is a divergent member of the TGF- $\beta$ superfamily. Proc Natl Acad Sci USA 94: 11514-11519.

36. Ramirez JM, Schaad O, Durual S, Cossali D, Docquier M, et al. (2009) Growth differentiation factor 15 production is necessary for normal erythroid differentiation and is increased in refractory anaemia with ring-sideroblasts. Br J Haematol 144: 251-262.

37. Kempf T, Sinning JM, Quint A, Bickel C, Sinning C, et al. (2009) Growthdifferentiation factor- 15 for risk stratification in patients with stable and unstable coronary heart disease: results from the AtheroGene study. Circ Cardiovasc Genet 2: 286-292.

38. Zaidi SH, Huang Q Momen A, Riazi A, Husain M (2010) Growth differentiation factor 5 regulates cardiac repair after myocardial infarction. J Am Coll Cardiol 55: 135-143.

39. Tanno T, Porayette P, Sripichai O, Noh SJ, Byrnes G, et al. (2009) Identification of TWSG1 as a second novel erythroid regulator of hepcidin expression in murine and human cells. Blood 114: 181-186.

40. Arosio P, Ingrassia R, Cavadini P (2009) Ferritins: a family of molecules for iron storage, antioxidation and more. Biochim Biophys Acta 1790: 589-599.

41. Gandon Y, Olivié D, Guyader D, Aubé C, Oberti F, et al. (2004) Non-invasive assessment of hepatic iron stores by MRI. Lancet 363: 357-362.

42. St Pierre TG, Clark PR, Chua-anusorn W, Fleming AJ, Jeffrey GP, et al. (2005) Noninvasive measurement and imaging of liver iron concentrations using proton magnetic resonance. Blood 105: 855-861.

43. Armand P, Kim HT, Rhodes J, Sainvil MM, Cutler C, et al. (2011) Iron Overload in Patients with Acute Leukemia or MDS Undergoing Myeloablative Stem Cell Transplantation. Biol Blood Marrow Transplant 17: 852-860.

44. Valenti L, Girelli D, Valenti GF, Castagna A, Como G, et al. (2009) HFE mutations modulate the effect of iron stores and inflammation on serum hepcidin-25 in chronic hemodialysis patients. Clin J Am Soc Nephrol 4: 1331-1337.

45. Girelli D, Trombini P, Busti F, Campostrini N, Sandri M, et al. (2010) A time course of hepcidin response to iron challenge in HFE and TfR2 Haemochromatosis patients. Haematologica 96: 500-506.

46. Nemeth E, Valore EV, Territo M, Schiller G, Lichtenstein A, et al. (2003) Hepcidin, a putative mediator of anemia of inflammation, is a type II acutephase protein. Blood 101: 2461-2463.

47. Wessling-Resnick M (2010) Iron homeostasis and the inflammatory response. Annu Rev Nutr 30: 105-122.

48. Sasu BJ, Cooke KS, Arvedson TL, Plewa C, Ellison AR, et al. (2010) Antihepcidin antibody treatment modulates iron metabolism and is effective in a mouse model of inflammation-induced anemia. Blood 115: 3616-3624.

49. Poli M, Girelli D, Campostrini N, Maccarinelli F, Finazzi D, et al. (2011) Heparin: a potent inhibitor of hepcidin expression in vitro and in vivo. Blood 117: $997-1004$. 